\title{
Properties of coatings created by HVOF technology using micro- and nano-sized powder
}

\author{
Guzanová A. ${ }^{1}$, Brezinová J. ${ }^{1}$, Draganovská D. ${ }^{1}$, Maruschak P.O. ${ }^{2}$ \\ ${ }^{1}$ Technical University of Košice, Faculty of Mechanical Engineering, Department of Mechanical \\ Technology and Materials, Slovakia \\ 2 Ternopil Ivan Pul'uj National Technical University, Ternopil, Ukraine \\ E-mail: anna.guzanova@tuke.sk
}

The paper focuses on assessment the resistance of hot-sprayed coatings applied by $\mathrm{HVOF}$ technology (WC-Co-Cr created using powder of two different grain sizes) against erosive wear by dry-pot wear test in a pin mill at two sample angles. As these coatings are designated for the environment with varying elevated temperatures and often are in contact with the abrasive, the coatings have been subjected to thermal cyclic loading and their erosive resistance has been determined in as-sprayed condition and after the $5^{\text {th }}$ and $10^{\text {th }}$ thermal cycles. The corrosion resistance of coatings was evaluated by linear polarization (Tafel analysis).

\section{INTRODUCTION}

Thermal spraying is well-established technology for restoration worn surfaces of machine parts, adding worn dimensions, obtaining a hard and durable surface layer on various types of components, especially of cylindrical and ball shape - rollers, ball valves, etc. [1,2] In spite of the steady range of powders for thermal spraying, new materials [3-5] are developed and scientist permanently experiment in this area. One way to change the properties of coatings and adapt them to a specific application is to change the type of carbide, change the matrix composition, change the volume content of carbide in the matrix [6-13]. It is also considered that also the reduction in the particle size of the powder used may lead to improvements in some properties. Therefore, the contribution aims to determine the effect of changing the powder particle size on its resulting properties (hardness, wear resistance and corrosion rate) while preserving the chemical composition as well as the volume of components.

\section{MATERIALS AND METHODS}

The test samples were made of medium carbon steel STN 412040 (the most widely used for machinery parts, normalized). The samples had a cylindrical shape tailored to clamping into the test device (Fig. 1). Two types of coatings were applied by HVOF (high velocity oxygen fuel) technology to the front side of test samples.

Surface preparation of the base material for coating application was performed by abrasive blasting using white corundum with grit size between $0.71-1.00 \mathrm{~mm}$, air pressure of $0.4 \mathrm{MPa}$, blasting distance of $300 \mathrm{~mm}$, blasting angle of $90^{\circ}$. For coatings deposition, one type of powder (WC-Co-Cr) was used in two powder particle sizes (samples marked M: 3-17 $\mu \mathrm{m}$ and samples marked $\mathrm{N}: 1-9 \mu \mathrm{m})$. Figure 2 shows the powder morphology.

The coatings were applied by HVOF technology using spraying equipment JP-5000 from Praxair TAFA. Spraying parameters corresponded to the parameters recommended by the powder manufacturer. Coatings were exposed to ten thermal cycles, test samples were collected after 5 and 10 thermal cycles. One thermal cycle consists of heating the samples to $600^{\circ} \mathrm{C}$, holding at this temperature for 20 minutes and cooling in still air for 20 minutes.

The sample marking system was as follows: M0, M5, M10 - coating M, 0, 5 and 10 thermal cycles N0, N5, N10 - coating N, 0, 5 and 10 thermal cycles

The coatings at the given thermal load stage were subsequently subjected to a metallographic analysis, Vickers hardness test (HV 0.1) and coating thickness measurement. Testing the erosion resistance of the coatings has followed. 
Erosive wear of coatings was evaluated by a drypot wear test in a pin mill at two sample angles. Testing device is shown in Figure 3. A brown corundum with particle size of $1.2 \mathrm{~mm}$ was used as the testing abrasive. Six samples of $M$ were fastened to the holder, three of them were inclined at an angle of $45^{\circ}$ and another three at an angle of $90^{\circ}$ toward direction of movement (Fig. 4). The velocity of movement of the samples with the coatings was $1.74 \mathrm{~m} \mathrm{~s}^{-1}$, the depth of immersion of the samples in the abrasive $70 \mathrm{~mm}$, the weight loss of the coatings was measured every 60 minutes, total duration of the test was 8 hours. Prior to each coating weight measurement, samples were thoroughly cleaned and dried.

Corrosion resistance of coatings was assessed by potentiodynamic test in $3.5 \% \mathrm{NaCl}$ solution. Tests were performed on a Potentiostat SP 150 device (Bio-Logic
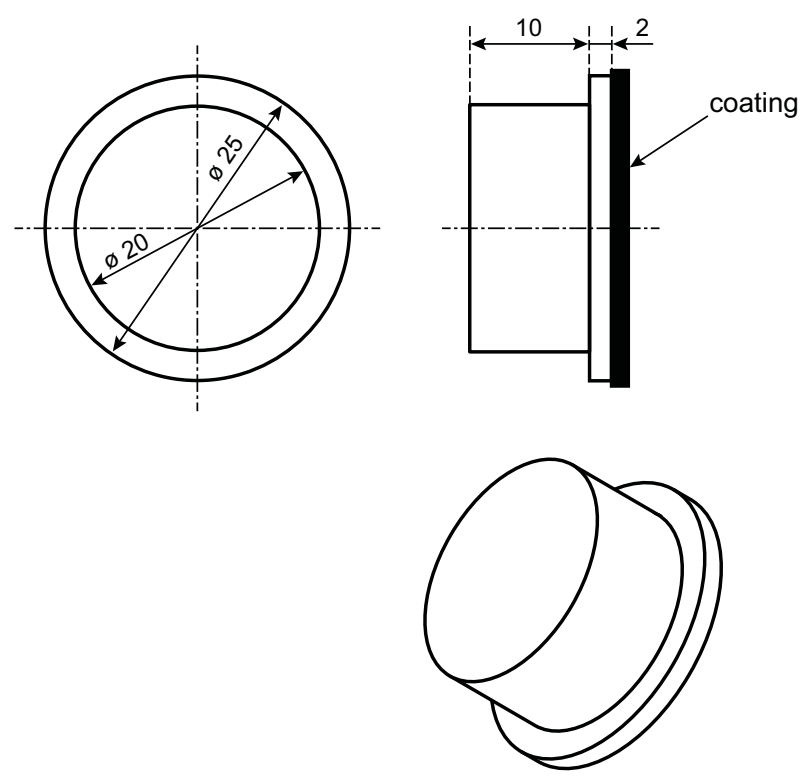

Fig. 1. Test samples

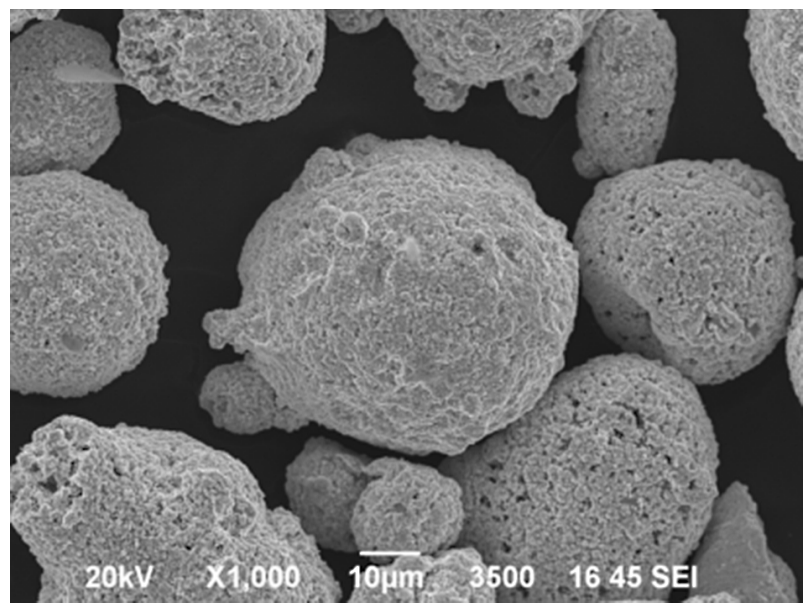

Fig. 2. Morphology of WC-Co-Cr powder
Science Instruments, Claix, France) and were processed using EC-Lab V10 software (version V10, Bio-Logic Science Instruments, Claix, France). A saturated calomel electrode (SCE) was used as the reference electrode, platinum (Pt) was used as an auxiliary electrode and coating was used as working electrode. The start of the measurement procedure consisted of stabilizing the electrode potential $\mathrm{Er}(\mathrm{V})$ over a time interval of $30 \mathrm{~min}$.

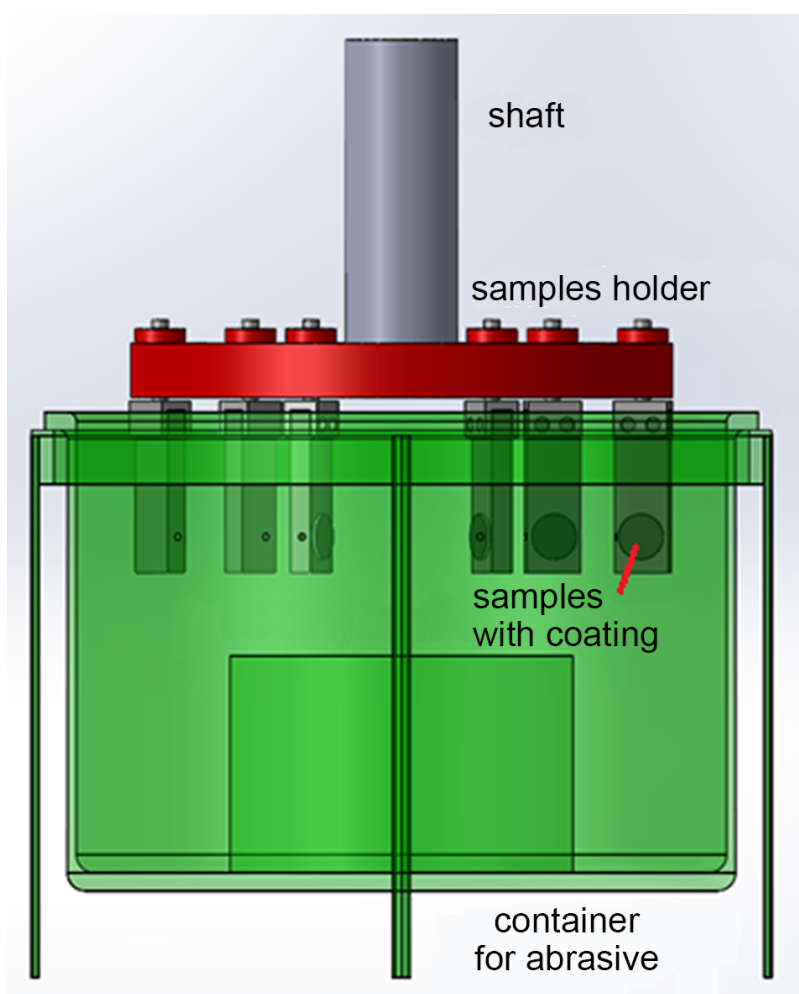

Fig. 3. Testing device for dry-pot wear test

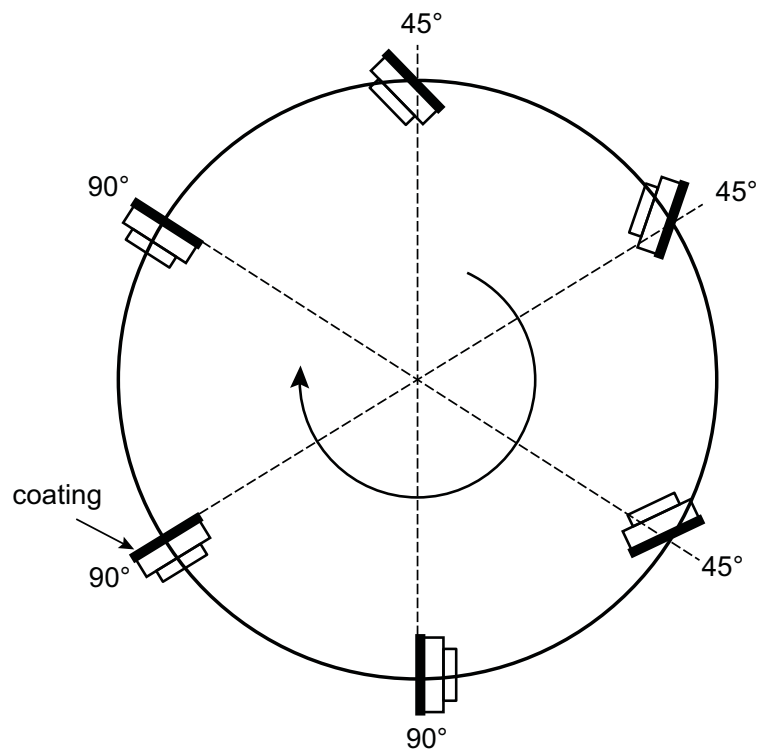

Fig. 4. Scheme of contact geometry 
The software recorded values every 5 seconds or $5 \mathrm{mV}$. Polarization ranged from $-0.25 \mathrm{mV}$ to $0.25 \mathrm{mV}$ against a calomel electrode at a polarization rate of $1 \mathrm{mV} \mathrm{s}^{-1}$. At the end of the time sequence, the values most closely related to the values of the observed potential were recorded. The resulting current densities, depending on the inserted potential, were plotted in semi logarithmic coordinates and analysed by Tafel analysis. The result of the analysis are following values - corrosion potential $\mathrm{E}_{\text {corr }}$, corrosion current $\mathrm{I}_{\text {corr }}$ and corrosion rate $\mathrm{V}_{\text {corr }}$ calculated from $\mathrm{E}_{\text {corr }}$ and $\mathrm{I}_{\text {corr }}$.

For the detection of phase transformation in coatings during thermal cycles, environmental scanning electron microscope SEM EVO MA15 (Carl Zeiss, Germany) with integrated analytical units EDX and WDX (Oxford Instruments, United Kingdom) was used. Diffraction measurements were performed on a Philips X'Pert PRO device using $\mathrm{Cu}$ radiation. The phase composition of the samples was determined using the PDF2 database and the subsequent Rietveld structure refinement was performed using the MAUD software.

\section{RESULTS AND DISCUSSION}

Fracture areas of coatings M0 and N0 as-sprayed are shown in Figures 5 and 6.

It can be seen that the as-sprayed coatings possess a dense structure with small pores well distributed in the coating. Some micro-cracks are also found in both coatings, which are caused by the thermal stress induced in HVOF spray process.

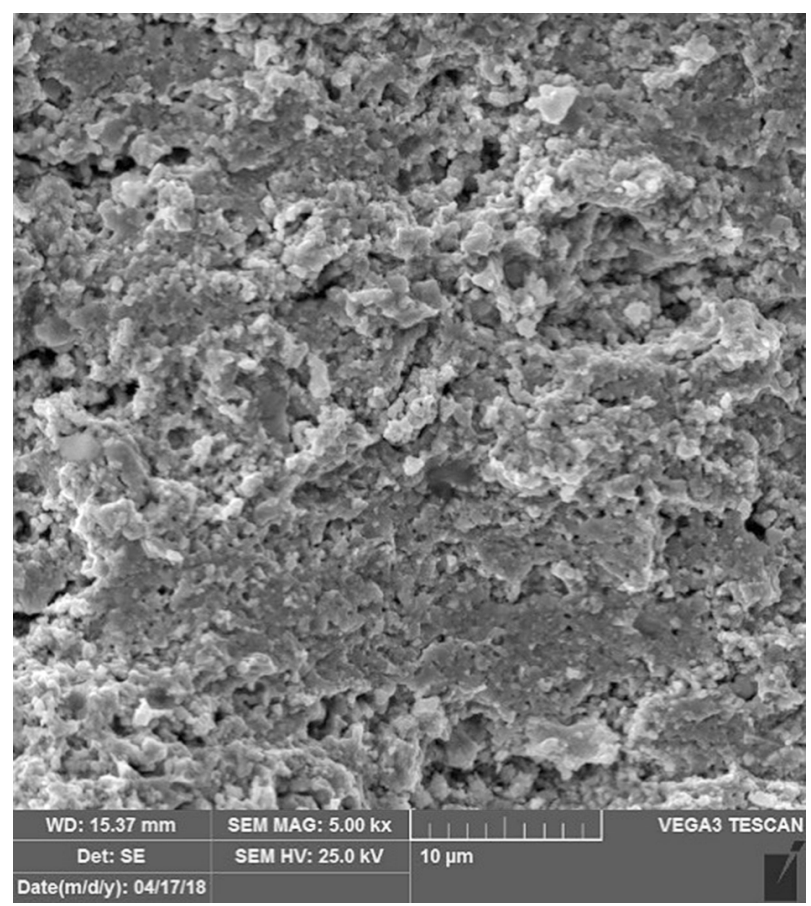

Fig. 5. Fracture area of coating MO (SEM)
Metallographic cross-section and the thickness of the coatings $\mathrm{M}$ and $\mathrm{N}$ after five thermal cycles can be seen in Figures 7 and 8.

The images show dense and a homogeneous coating structure. The average thickness of the coating $M$ was $468 \pm 5 \mu \mathrm{m}$ and the coating $\mathrm{N} 230 \pm 12 \mu \mathrm{m}$. The different coating thickness was caused by the manual controlling the coating thickness only by the number of spray nozzle transitions over the substrate. Since the powder used had a different grain size, it was manifested by a different coating thickness. The different thickness of the coatings did not affect the wear resistance test, since the base material didn't become worn through in any case during the test and thus didn't affect the test results.

The hardness of the base material was $290 \mathrm{HV} 0.1$. In Table 1, hardness values (average of 10 measurements) of coating $\mathrm{M}$ and $\mathrm{N}$ measured as a function of thermal stress can be found.

Table 1 shows greater hardness of coating N compared to M. Yang [14] and Pengbo [15] reported that the high hardness of the WC-Co coating with nano-powder coating are attributed to the hardening effect from the nano-sized WC particles distributing in Co phase, and the large cracking surface area and the crack bridging, respectively. With an increasing number of thermal cycles, the hardness of the coatings increased. This change can be related to the phase changes, that occur in the coating during thermal cyclic loading, as will be shown in the following.

Figures 9 and 10 show the mass losses of the individual coatings at different thermal load conditions and at different sample angles.

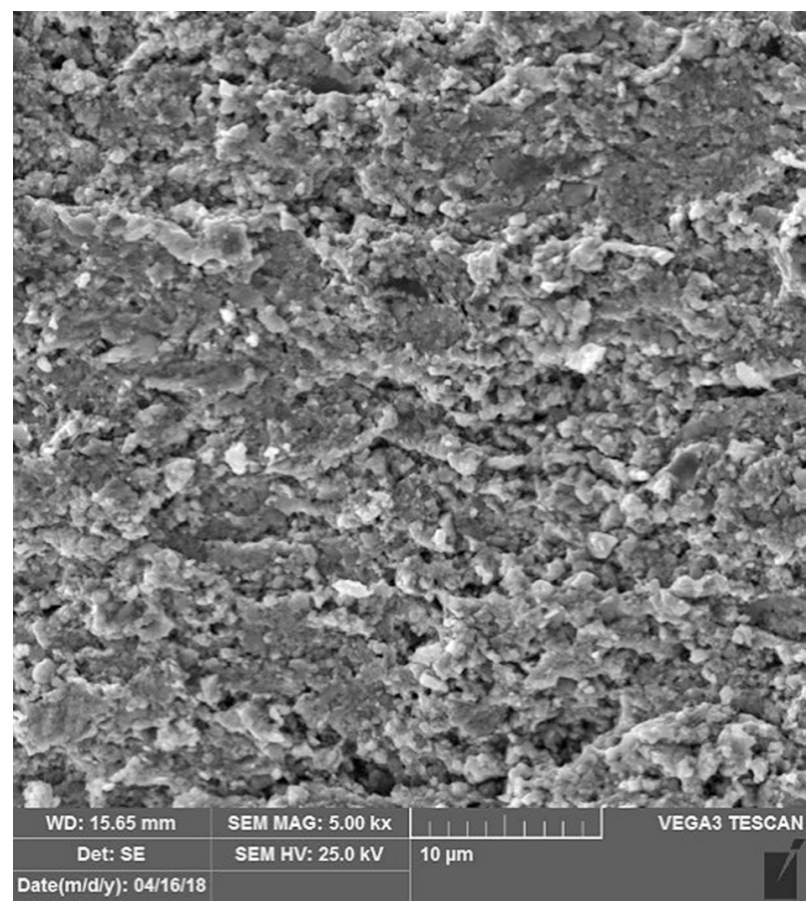

Fig. 6. Fracture area of coating NO (SEM) 


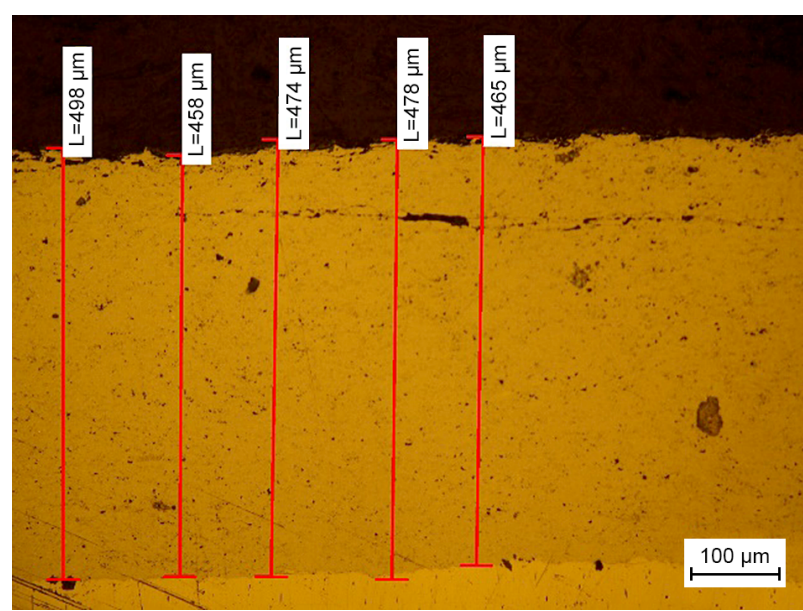

Fig. 7. Metallographic cross-section and the thickness of coating M5

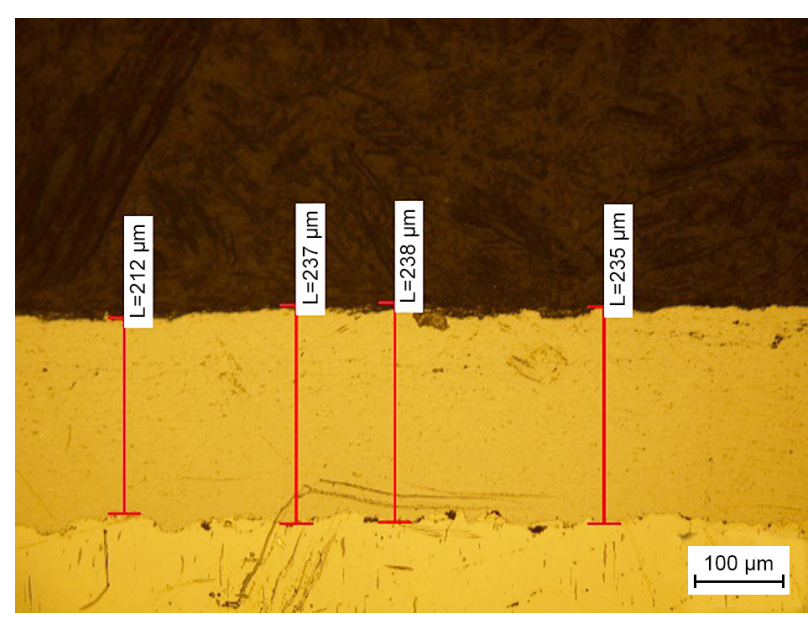

Fig. 8. Metallographic cross-section and the thickness of coating N5

The test proved slightly higher wear resistance of coating $\mathrm{N}$ compared to $\mathrm{M}$ (Fig. 9, Fig. 10).

The slightly higher wear resistance of the $\mathrm{N}$ coating can be explained by the smaller size of the carbide WC particles. In coating $\mathrm{WC}-\mathrm{Co}-\mathrm{Cr}$ made of nanopowder, the number of WC particles in a volume unit is higher than when using WC particles of greater size. Since, according to [16], the wear resistance of the matrix is lower than the WC particle, the matrix undergoes wear earlier. Due to the larger number of WC particles in the nanocoating volume, and logically also on the abrasive contact surface during the wear test, contact area between the abrasive and the matrix is lower and it results in a slightly lower weight loss of nanocoating.

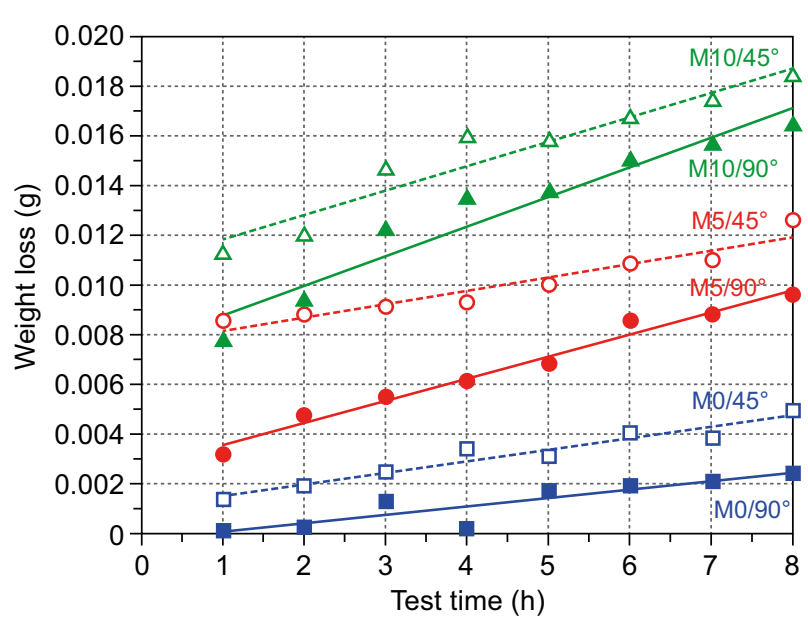

Fig. 9. Mass loss of $M$ coating

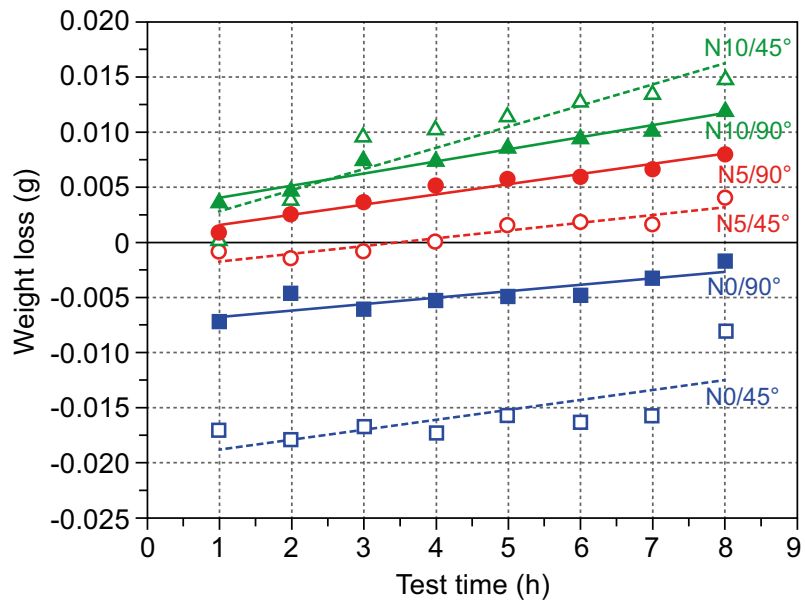

Fig. 10. Mass loss of $\mathrm{N}$ coating

Regarding the effects tested - thermal cyclic loading and sample angle, it is clear that the thermal cyclic loading affects the resistance of the coatings more significantly than sample angle. Thermal cyclic loading of coatings reduces their wear resistance. For the vast majority of samples, there was a more pronounced wear at an angle of $45^{\circ}$.

Thermal cyclic loading was accompanied with change of coating's colour, which indicate also some phase changes. Therefore phase analysis was performed Figure 11.

In both coatings, new oxide phases of $\mathrm{CoWO}_{4}$ and $\mathrm{WO}_{3}$ appear after thermal cyclic stress. The share of oxide phases in the coatings increases with increasing number of thermal cycles. This is manifested by an increase in the intensity of the reflections corresponding

Tab. 1. Hardness of coatings HV 0.1

\begin{tabular}{|c|c|c|c|c|c|}
\hline M0 & M5 & M10 & N0 & N5 & N10 \\
\hline $1280 \pm 19$ & $1750 \pm 17$ & $1770 \pm 16$ & $1570 \pm 19$ & $1750 \pm 25$ & $1920 \pm 23$ \\
\hline
\end{tabular}


to the oxides and a relative decrease in the intensity of the reflections of the WC phase against the oxides reflections. It can also be seen that with the increasing number of thermal fatigue, the $\mathrm{CoWO}_{4}$ oxide phase increases more rapidly. Changes in the hardness and

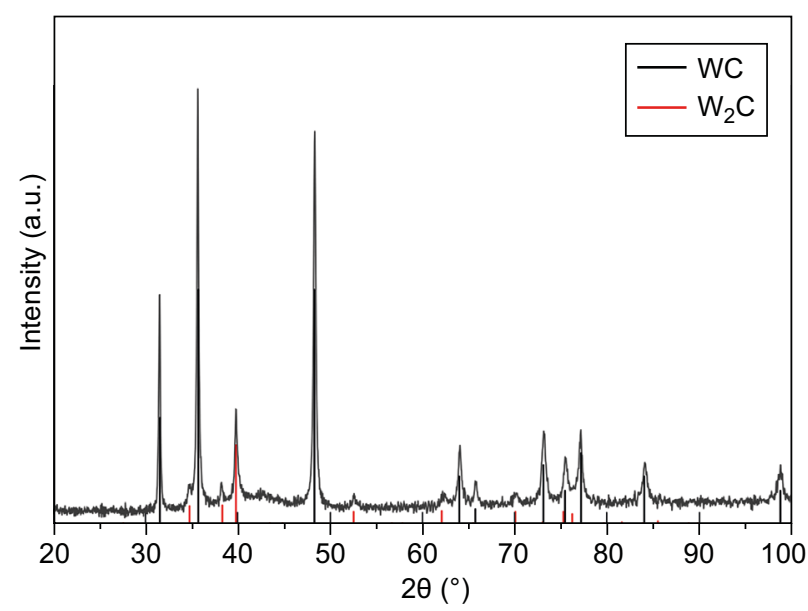

a) $\mathrm{MO}$

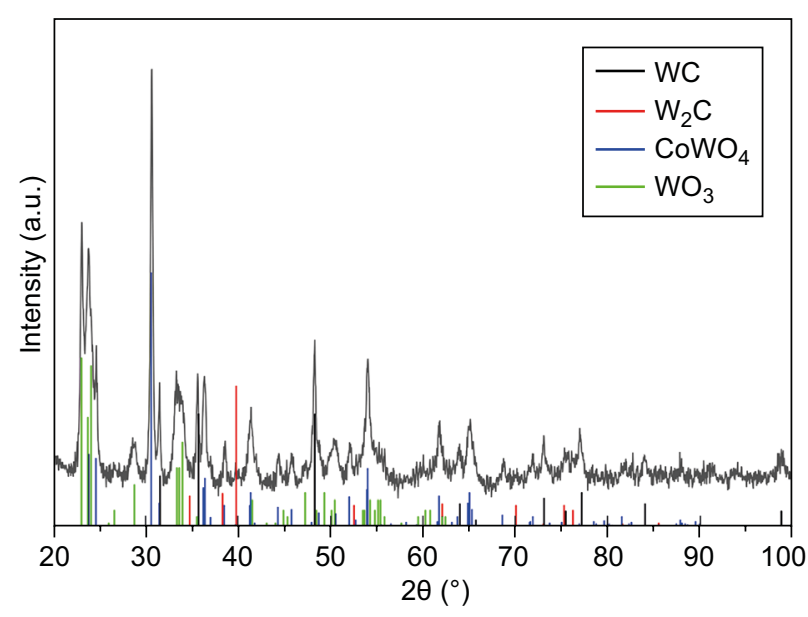

c) M5

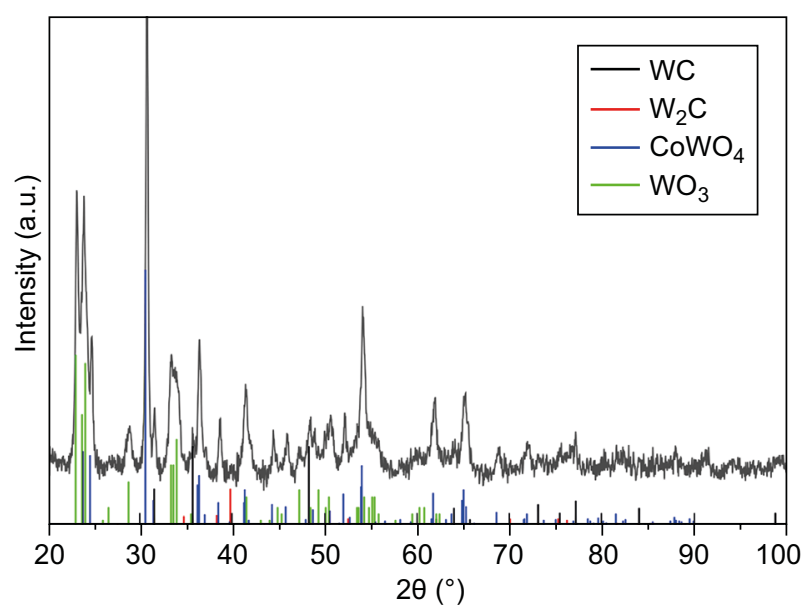

e) M10 wear resistance of coatings after thermal cyclic loading can be attributed to emerging oxide phases.

For determination of the wear mechanism, the surfaces of the worn samples were studied. The appearance of the worn surfaces is shown in Figure 12.

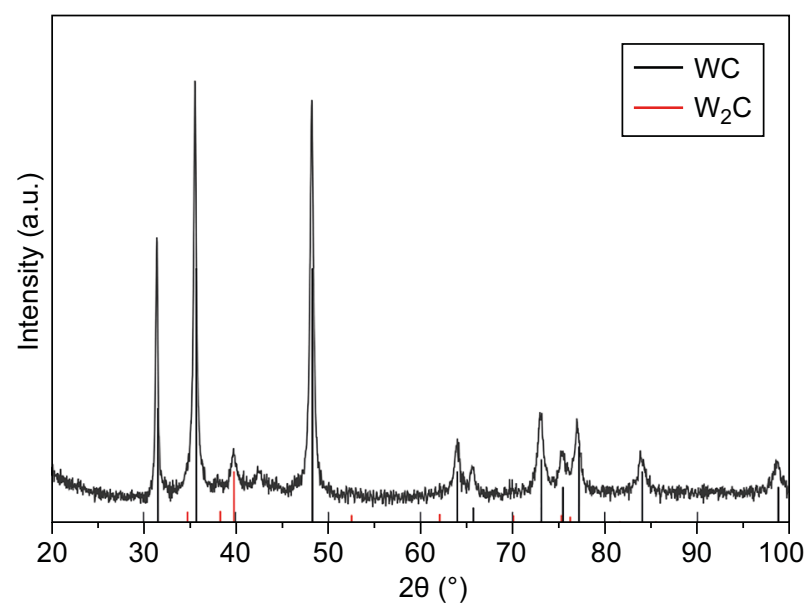

b) NO

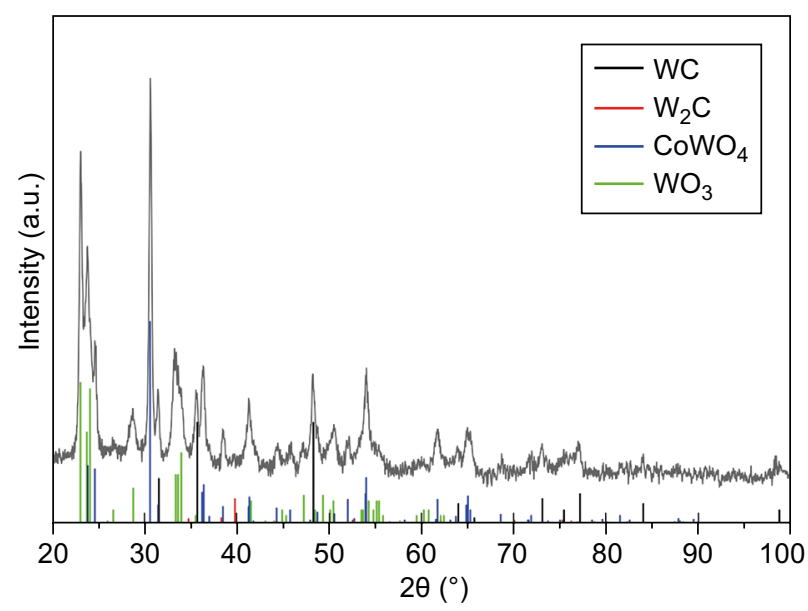

d) N5

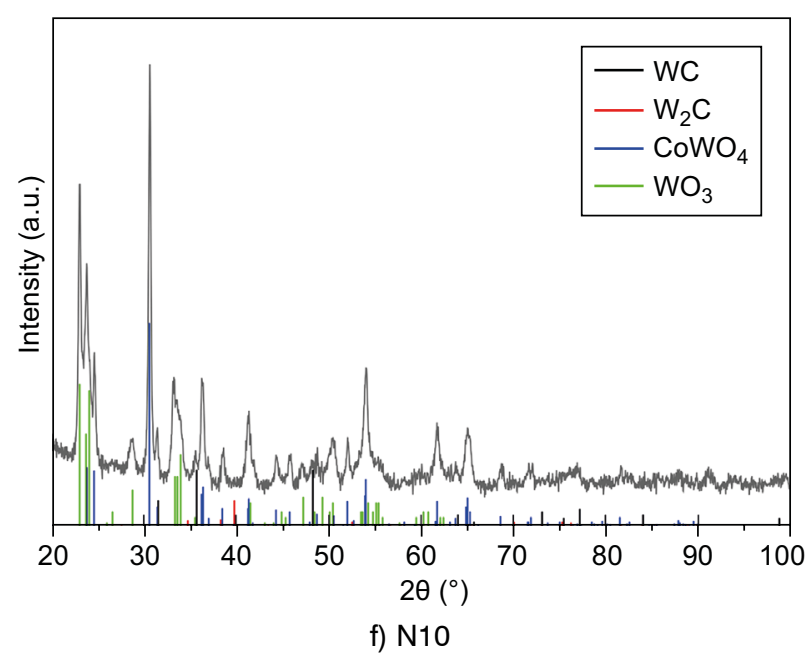

Fig. 11. Diffraction pattern of coatings 
Figure 12-right shows that in "as-sprayed" state at impact angle $90^{\circ}$, the wear surface of the coatings consists of many craters formed by the mutual movement of the abrasive particles and the coating. Craters were formed by pulling out the particles and spalling of the coating. In some areas, pulled out areas are surrounded by an edge indicating strain localization, which is characteristic of ductile wear mode. In coatings without thermal cyclic coating, ductile wear mode interfere probably in $\mathrm{Co}-\mathrm{Cr}$ metal binder phase. After thermal

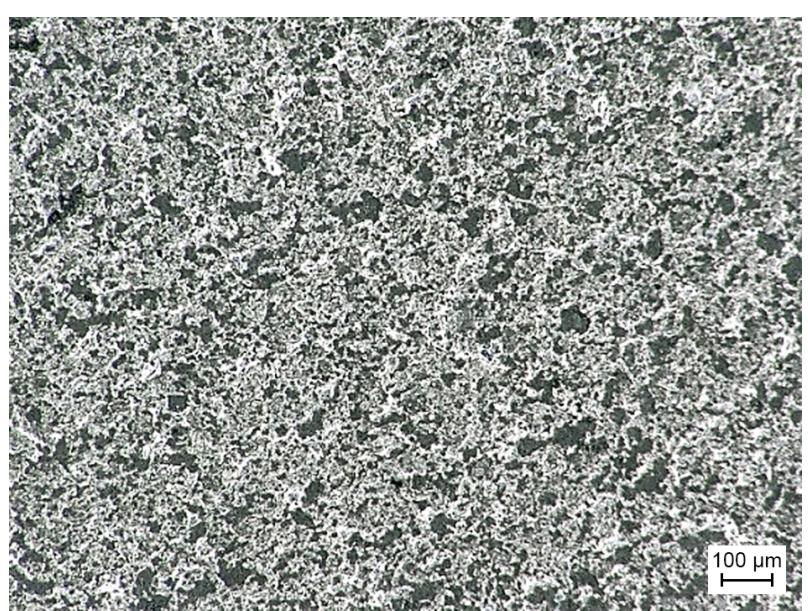

a) $\mathrm{MO} / 45^{\circ}$

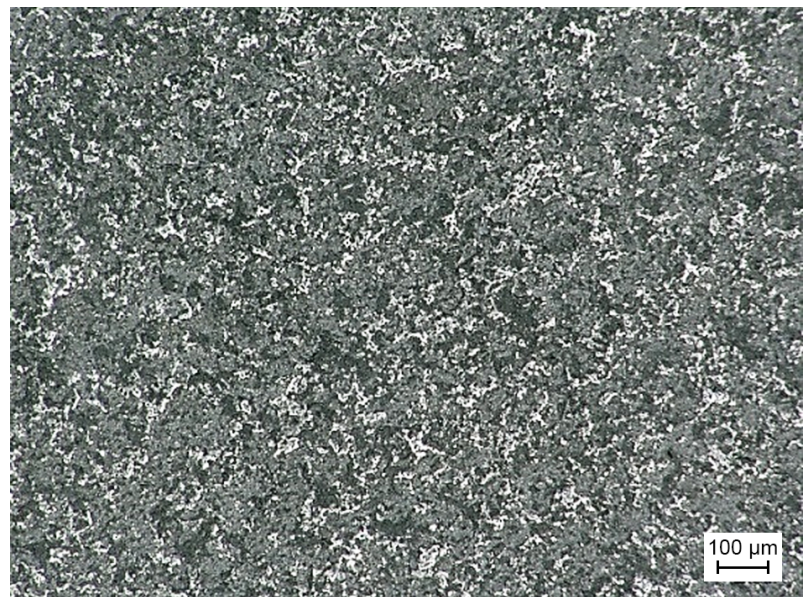

c) $\mathrm{M} 10 / 45^{\circ}$

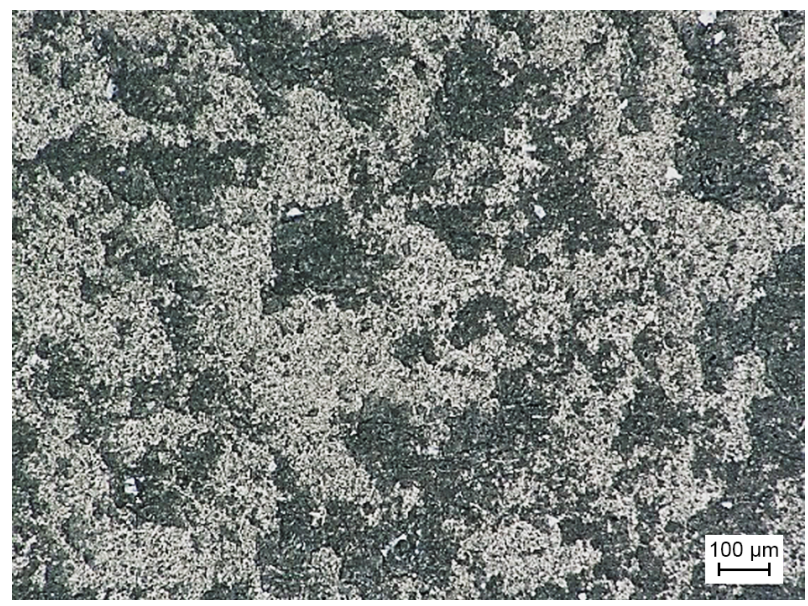

e) $\mathrm{N} 0 / 45^{\circ}$

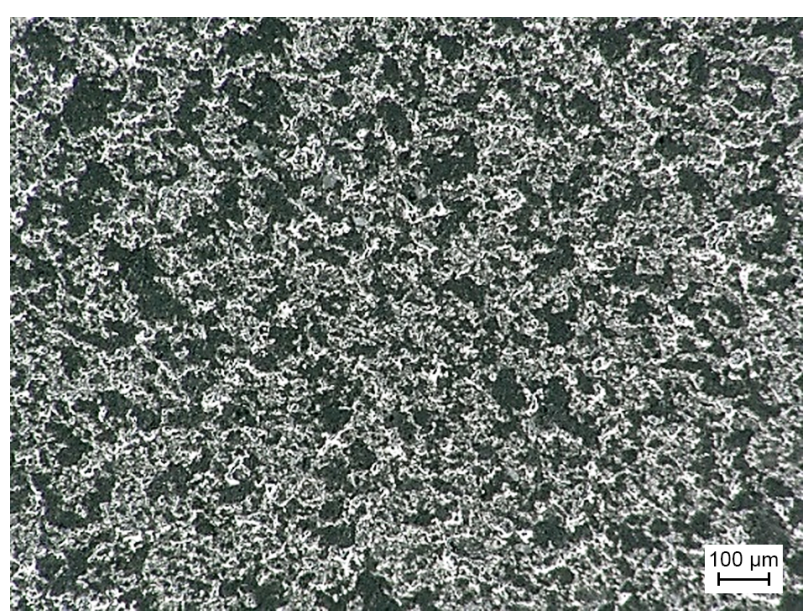

b) $\mathrm{Mo} / 90^{\circ}$

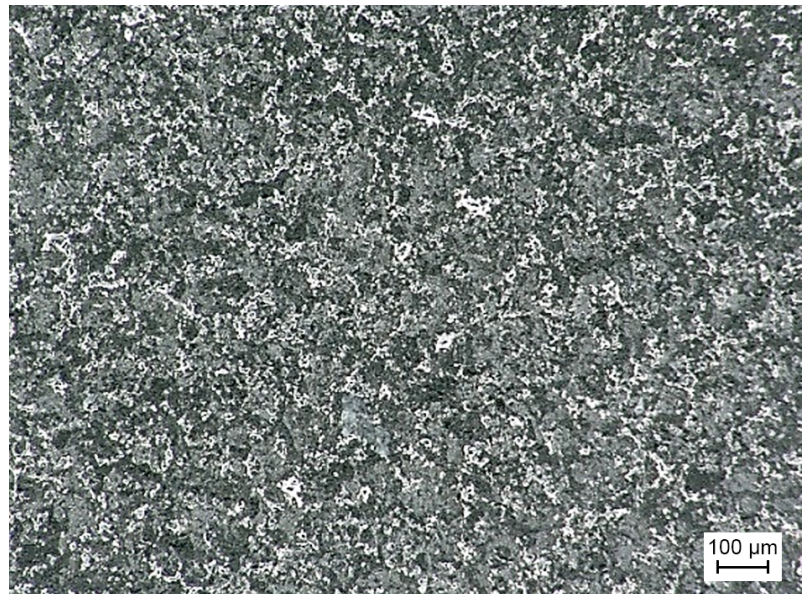

d) $\mathrm{M} 10 / 90^{\circ}$

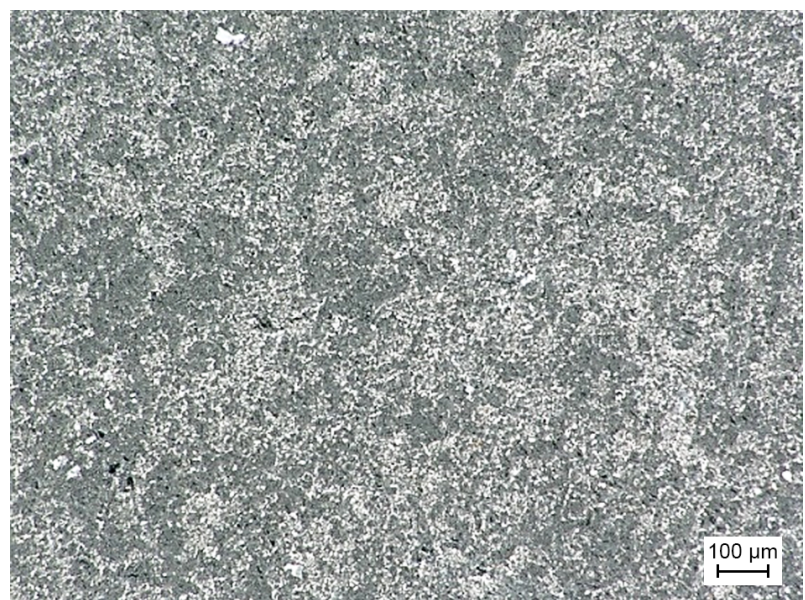

f) $\mathrm{N} 0 / 90^{\circ}$

Fig. 12. Surface appearance of worn coatings (continue on next page) 


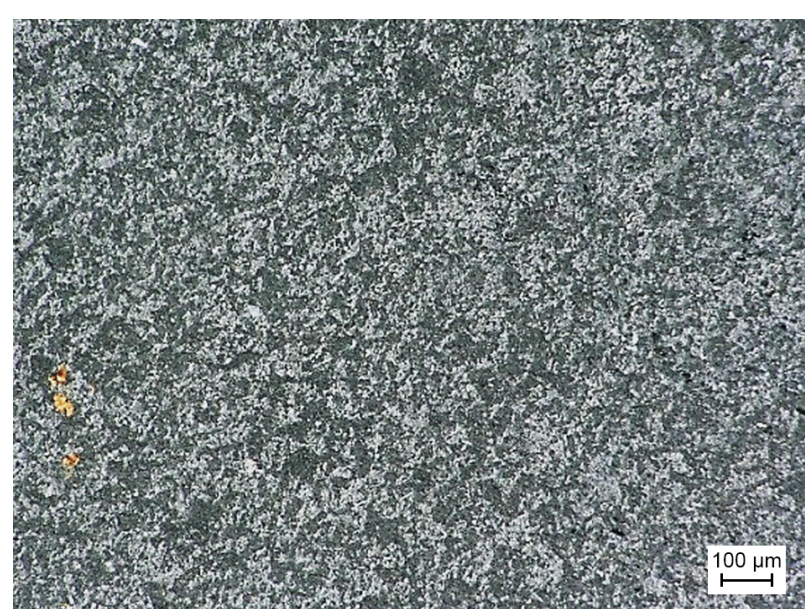

g) $\mathrm{N} 10 / 45^{\circ}$

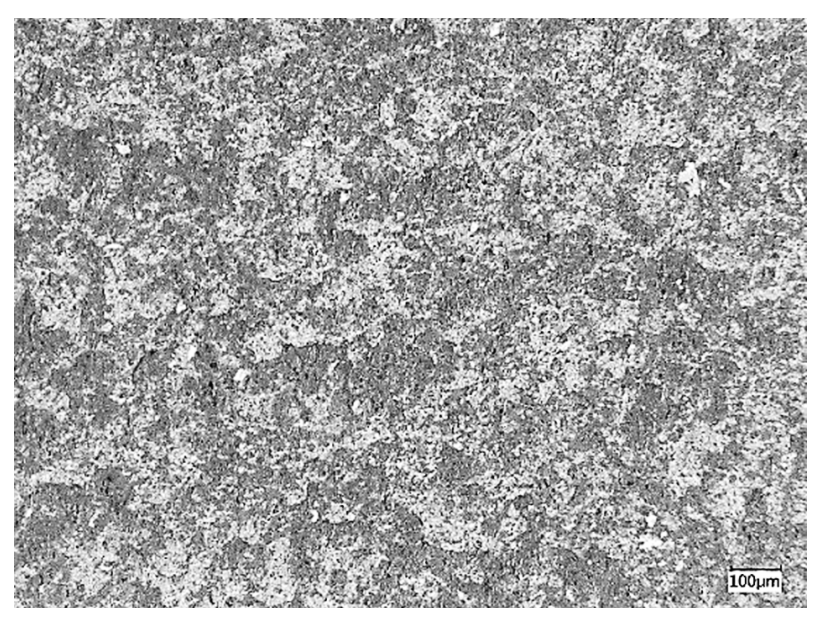

h) $\mathrm{N} 10 / 90^{\circ}$

Fig. 12. Surface appearance of worn coatings

cycling loading of coatings, the failure mechanism involved removing the material by pulling out, fractures of the carbide particles and ripping them out of the binder phase (Fig. 12 - coatings after 10 thermal cycles), so brittle failure mode dominates. A similar trend is observed at an oblique impact (Fig. 12-left). For example, "as sprayed" coatings tested at a $45^{\circ}$ impact angle consisted of deeper grooves in the direction of abrasive particles impact due to ploughing of abrasive particles on the coatings.

Table 2 shows results of potentiodynamic test carried out on the coatings. Figures 13 and 14 show the potentiodynamic polarization curves of coatings.

Corrosion potential values for coating $\mathrm{M}$ ranged from -482 to $-180 \mathrm{mV}$. As a result of thermal cyclic load, $\mathrm{E}_{\text {corr }}$ values have increased. Corrosion current density $\mathrm{I}_{\text {corr }}$ values ranged from 4.855 to $34.285 \mu \mathrm{A}$. These values also decreased due to thermal cycles. The corrosion rate $r_{\text {corr }}$ was calculated in the range of 0.32 to $2.21 \mathrm{~mm} /$ year. This coating proved higher corrosion resistance after thermal loading compared to as-sprayed.

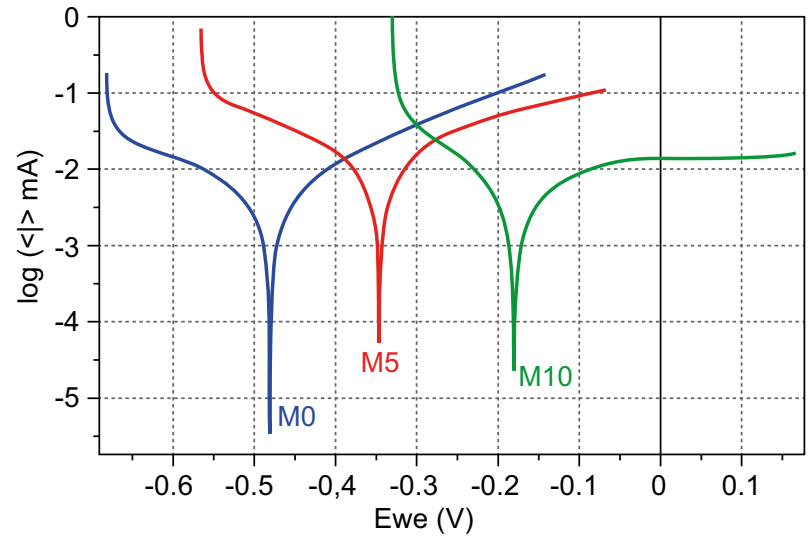

Fig. 13. Potentiodynamic polarisation curves (coating $M$ )
Similarly, corrosion potential values for coating N ranged from -486 to $-234 \mathrm{mV}$. As a result of thermal cyclic load, $\mathrm{E}_{\text {corr }}$ values have increased. Corrosion current density $\mathrm{I}_{\text {corr }}$ values ranged from 4.495 to $25.574 \mu \mathrm{A}$. These values also decreased due to thermal cycles. The corrosion rate $\mathrm{v}_{\text {corr }}$ was calculated in the range of 0.29 to $1.65 \mathrm{~mm} /$ year. This coating also proved higher corrosion resistance after thermal loading compared to as-sprayed.

Tab. 2. Corrosion resistance of coatings

\begin{tabular}{|l|c|c|c|c|c|c|}
\hline Coating & M0 & M5 & M10 & N0 & N5 & N10 \\
\hline $\mathrm{E}_{\text {corr }}(\mathrm{mV})$ & -482 & -388 & -180 & -486 & -252 & -234 \\
\hline $\mathrm{I}_{\text {corr }}(\mu \mathrm{A})$ & 7.3 & 34.3 & 4.9 & 25.6 & 5.3 & 4.5 \\
\hline$\beta \mathrm{c}(\mathrm{mV})$ & 314 & 470 & 104 & 494 & 150 & 117 \\
\hline$\beta \mathrm{a}(\mathrm{mV})$ & 245 & 471 & 352 & 200 & 264 & 214 \\
\hline $\mathrm{r}_{\text {corr }}(\mathrm{mm} / \mathrm{y})$ & 0.47 & 2.21 & 0.32 & 1.65 & 0.34 & 0.29 \\
\hline
\end{tabular}

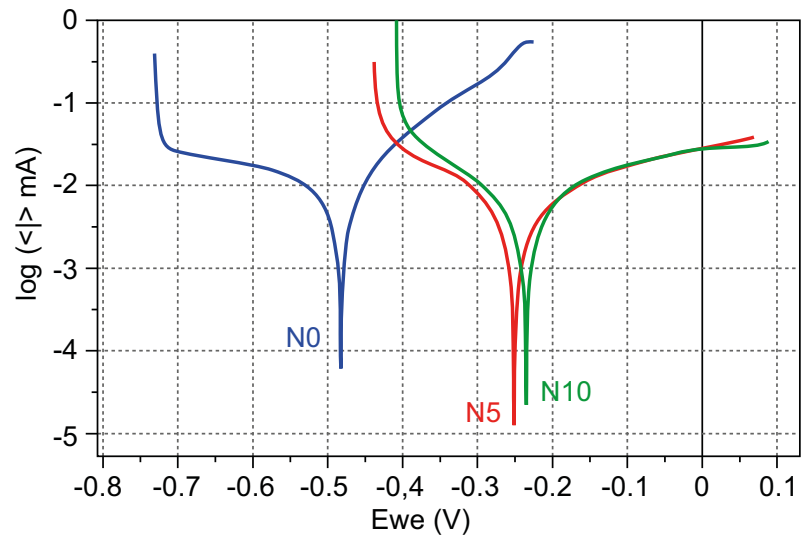

Fig. 14. Potentiodynamic polarisation curves (coating N) 


\section{CONCLUSIONS}

By summarization the results, it can be stated that a coating made of powder with a lower particle size (1-9 $\mu \mathrm{m})$, which already belongs to the nanopowder coatings, has a higher hardness, wear resistance and almost the same corrosion resistance compared to the coating made of powder with a particle size of 3-17 $\mu \mathrm{m}$.

The higher hardness of coating made of nanopowder is related to the smaller WC carbide dimensions and their different distribution in the $\mathrm{CoCr}$ matrix. The hardness of the coatings increased during the thermal cyclic load, due to phase changes, namely the formation of new $\mathrm{CoWO}_{4}$ and $\mathrm{WO}_{3}$ oxide phases, absent in the original coating. During cyclic loading, the proportion of these phases, especially the $\mathrm{CoWO}_{4}$ phase, continuously increased. The emergence of new phases took place at the expense of the WC phase, which was manifested by the reduction of reflections of the WC phase. The new phases affected not only the hardness but also the erosion resistance of the coatings.

Phase changes also affected the mechanism of coating failure in erosion. The phase change, in particular the transformation of the $\mathrm{WC}$ to $\mathrm{CoWO}_{4}$ and $\mathrm{WO}_{3}$, weakened the adhesion between the WC particles and $\mathrm{CoCr}$ matrix, resulting in a more intense release of particles from the matrix and higher weight loss. The nature of detaching particles from the matrix has changed from ductile to brittle.

These properties can be used in the field of renovation and protection of surfaces of more stressed machine parts. The important contribution of this research work is the knowledge that changing the granularity of powders for thermal spraying of metal-ceramic coatings is a prospective way, how to suitably affect the properties of coatings without changing their chemical composition.

\section{Acknowledgements}

This work was supported by the Ministry of Education, Science, Research and Sport of the Slovak Republic (VEGA 1/0424/17).

\section{REFERENCES}

1. Tan J.C., Looney L., Hashmi M.S.J. Component repair using HVOF thermal spraying, Journal of Materials Processing Technology 1999, 92-93, 203-208.
2. Oksa M. et al. Optimization and Characterization of High Velocity Oxy-fuel Sprayed Coatings: Techniques, Materials, and Applications, Coatings 2011, 1, 17-52.

3. Nahvi S.M., Jafari M. Microstructural and mechanical properties of advanced HVOF-sprayed WC-based cermet coatings, Surface and Coatings Technology 2016, 286, 95-102.

4. Zhou W. et al. High temperature wear performance of HVOF-sprayed $\mathrm{Cr}_{3} \mathrm{C}_{2}-\mathrm{WC}-\mathrm{NiCoCrMo}$ and $\mathrm{Cr}_{3} \mathrm{C}_{2}-\mathrm{NiCr}$ hardmetal coatings, Applied Surface Science 2017, 416, $33-44$.

5. Bolelli $\mathrm{G}$. et al. Cermet coatings with Fe-based matrix as alternative to $\mathrm{WC}-\mathrm{CoCr}$ : Mechanical and tribological behavi-ours, Surface and Coatings Technology 2012, 206, 4079-4094.

6. Brezinová J. et al. Study of selected properties of thermally sprayed coatings containing WC and WB hard particles, Acta Mechanica et Automatica 2016, 10, 296-299.

7. Berger L.M. et al. Microstructure and Properties of WC $-10 \% \mathrm{Co}-4 \% \mathrm{Cr}$ Sprayed Powders and Coatings: Part. Powder Characterization, Journal of Thermal Spray Technology 2001, 10, 311-325.

8. Brezinová J. et al. Microstructure, Wear Behavior and Corrosion Resistance of WC-FeCrAl and WC-WB-Co Coatings, Metals 2018, 8, 399.

9. Brezinová J. et al. Quality Evaluation of HVOF Coatings on the Basis of WC-Co in Tribocorrosive Conditions, Materials Science Forum 2015, 811, 63-66.

10. Thakur L. et al. An investigation on erosion behavior of HVOF sprayed WC-CoCr coatings, Applied Surface Science 2011, 258, 1225-1234.

11. Cui S.Y. et al. Slurry Erosion Behavior of F6NM Stainless Steel and High-Velocity Oxygen Fuel-Sprayed WC-10Co4CrCoating, Journal of Thermal SprayTechnology 2017,26, 473-482.

12. Landová M., Brezinová J. Determination of selected properties and fracture toughness of HVOF coatings, Koroze a Ochrana Materialu 2016, 60, 128-131.

13. Ojala N. et al. Wear performance of quenched wear resistant steels in abrasive slurry erosion, Wear 2016, 354-355, 21-31.

14. Yang G.J., Gao P.H., Li C.X. et al. Simultaneous strengthening and toughening effects in WC-(nanoWC-Co), Scripta Materialia 2012, 66, 10, 777-780.

15. Mi P., Zhao H., Wang T., Ye F. Sliding wear behavior of HVOF sprayed WC-(nano-WC-Co) coating at elevated temperatures, Materials Chemistry and Physics 2018, 206, 1-6.

16. Mottaghi M., Ahmadian M. Comparison of the wear behavior of $\mathrm{WC} /(\mathrm{FeAl}-\mathrm{B})$ and $\mathrm{WC}-\mathrm{Co}$ composites at high temperatures, International Journal of Refractory Metals and Hard Materials 2017, 67, 105-114. 